DOI: https://doi.org/10.24867/13GI02Sudar

\title{
UTICAJ ORGANIZACIONE KLIME NA ZADOVOLJSTVO ZAPOSLENIH POSLOM U PROIZVODNOJ ORGANIZACIJI
}

\section{THE INFLUENCE OF THE ORGANIZATIONAL CLIMATE ON EMPLOYEE SATISFACTION WITH WORK IN A PRODUCTION COMPANY}

\author{
Jasmina Sudar, Fakultet tehničkih nauka, Novi Sad
}

\begin{abstract}
Oblast - INŽENJERSKI MENADŽMENT
Kratak sadržaj - Organizaciona klima je još od šezdesetih godina prošlog veka bila predmet istraživanja velikog broja radova u naučnoj i stručnoj literaturi zbog svoje važnosti u analizi i razumevanju organizacionog ponašanja i stavova zaposlenih u organizacijama. $U$ radu je istraživan uticaj organizacione klime na zadovoljstvo zaposlenih poslom u jednoj proizvodnoj organizaciji $i$ na osnovu rezultata je dat predlog mera koje bi trebale da doprinesu boljem poslovanju.
\end{abstract}

Ključne reči: Organizaciona klima, Zadovoljstvo poslom.

Abstract - Organizational climate has been the subject of research in a large number of papers in the scientific and professional literature since the 1960 s due to its importance in the analysis and understanding of organizational behavior and attitudes of employees in organizations. The paper investigates the influence of the organizational climate on employee satisfaction with work in a production organization and based on the results, a proposal of measures that should contribute to better business is given.

Key words: Organizational climate, employee satisfaction.

\section{UVOD}

Organizaciona klima je još od šezdesetih godina prošlog veka bila predmet istraživanja velikog broja radova u naučnoj i stručnoj literaturi zbog svoje važnosti u analizi i razumevanju organizacionog ponašanja i stavova zaposlenih u organizacijama. Sa druge strane, zadovoljstvo poslom jedan je od najvažnijih stavova koji imaju efekt na ponašanja ljudi u radnoj okolini. Da bi se razumeli stavovi zaposlenih potrebno je naći faktore koji bi mogli uticati na njihovo zadovoljstvo.

\section{ORGANIZACIJA I ODNOSI IZMEĐU ZAPOSLENIH}

\subsection{Pojam organizacije}

Organizacija predstavlja formalnu grupu ljudi koji imaju jedan ili više zajedničkih ciljeva i raspolažu određenim sredstvima i resursima. Uspostavljene su od strane države, privatnih lica ili građana, iz čega, uz različite načine

\section{NAPOMENA:}

Ovaj rad proistekao je iz master rada čiji mentor je bila dr Ljubica Duđak, vanr.prof. finansiranja, potiče podela na tri sektora - javni, privatni i civilno društvo. Organizacije se dele na one sa ciljom da kreiraju određene usluge $\mathrm{i}$ da ostvare profit, kako bi ostvarile određenu funkciju i na organizacije koje za cilj imaju brigu o pojedincima i društvene klime koje su najčešće neprofitne. I pored toga što nailazimo na različite definicije organizacija, one se takođe i različito shvataju.

\subsection{Organizaciona klima}

Početak istraživanja organizacione klime u raznim preduzećima, rezultirao je time da se organizacije ne razlikuju samo po fizičkoj strukturi, već i po stavovima i ponašanjima kod ljudi. Litwin i Stringer su definisali organizacionu klimu kao skup merljivih svojstava radnog okruženja, dok je sa vremenom ta definicija dobijala novi značaj, koji mi danas poznajemo. Sedamdesetih godina prošlog veka se smatralo da organizacijsku klimu čine sve percepcije iz radnog okruženja zaposlenih, koje se mogu razlikovati od organizacije do organizacije. Tek kasnije je organizaciona klima definisana kao zajednička percepcija zaposlenih o praksama, procedurama i ponašanjima na radnom mestu, a danas je jedno od definicija organizacione klime da ona predstavlja u stvari doživljaj internog okruženja organizacije od strane zaposlenih.

\section{STRUKTURA ORGANIZACIONE KULTURE}

Dominantna kultura sadrži vrednosti i verovanja koje dele svi njeni članovi. Dok subkultura sadrži samo one pretpostavke i verovanja koje deli jedna grupa zaposlenih. Postavlja se pitanje da li je organizaciona kultura celina ili je sastavljena od subkultura? Postoje tri perspektive strukture organizacione kulture (slika 1.):

- Perspektiva diferencijacije

- Perspektiva integracije

- Perspektiva fragmentacije

\subsection{Perspektiva diferencijacije}

Perspektiva diferencijacije podrazumeva da je organizaciona kultura složen system subkultura. Postoje dve varijante perspektivne diferencijacije (slika 2.):

- Kultura kao sistem subkultura

- Kultura kao skup dominantne kulture i subkultura 
PERSPEKTIVE STRUKTURE KULTURE

\begin{tabular}{|l|l|l|l|}
\hline & \multicolumn{1}{|c|}{ INTEGRACIJA } & \multicolumn{1}{|c|}{ DIFERENCIJACIA } & FRAGMENTACIJA \\
\hline $\begin{array}{l}\text { Konzistentnost } \\
\text { elemenata kulture }\end{array}$ & $\begin{array}{l}\text { Postoji na nivou } \\
\text { organizacione } \\
\text { kulture }\end{array}$ & $\begin{array}{l}\text { Postoji na nivou } \\
\text { subkultura, ne postoji na } \\
\text { nivou cele kulture }\end{array}$ & Ne postoji uopšte \\
\hline $\begin{array}{l}\text { Konsenzus } \\
\text { clanova oko } \\
\text { sadržaja }\end{array}$ & $\begin{array}{l}\text { Potpuna na nivou } \\
\text { organizacije }\end{array}$ & $\begin{array}{l}\text { Potpun na nivou } \\
\text { subkultura, nema ga na } \\
\text { nivou cele kulture }\end{array}$ & Ne postoji uopšte \\
\hline $\begin{array}{l}\text { Orijentacija ka } \\
\text { lideru }\end{array}$ & $\begin{array}{l}\text { Lider je centar } \\
\text { kulture }\end{array}$ & $\begin{array}{l}\text { Više centara kulture - } \\
\text { više lidera }\end{array}$ & $\begin{array}{l}\text { Nema centralne tačke } \\
\text { kulture }\end{array}$ \\
\hline $\begin{array}{l}\text { Neizvesnost i } \\
\text { nejasnoće }\end{array}$ & Ne postoje & $\begin{array}{l}\text { Postoje na nivou } \\
\text { subkultura, ne postoje } \\
\text { na nivou cele kulture }\end{array}$ & $\begin{array}{l}\text { Postoji u cuitavoj } \\
\text { kulturi }\end{array}$ \\
\hline Slika kulture & $\begin{array}{l}\text { Jedinstvena, } \\
\text { homogena, } \\
\text { monolitna }\end{array}$ & $\begin{array}{l}\text { Sistem dominirajuće } \\
\text { kulture i subkultura }\end{array}$ & $\begin{array}{l}\text { Mreža međusobno } \\
\text { labavo povezanih } \\
\text { vrednosti i simbola }\end{array}$ \\
\hline
\end{tabular}

Slika 1. Perspektive strukture kulture

\section{PERSPEKTIVA DIFERENCIJACIJE}

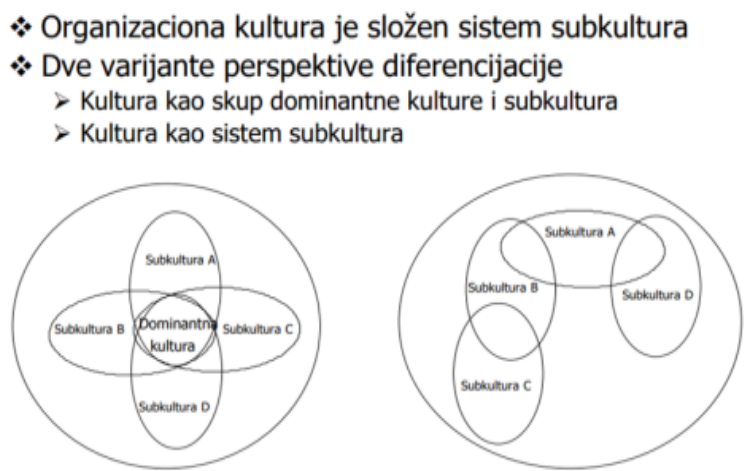

Slika 2. Perspektiva diferencijacije

\subsection{Perspektiva integracije}

Zasnovana je naprincipu jedna organizacija - jedna kultura, ako neke pretpostavke i vrednosti ne deli većina članova, one i nisu element sadržaja kulture. Ona je homogena, monolitna i kozistentnacelina.

Njene pretpostavke su sledeće:

- Centralna uloga lidera u kreiranju kulture

- Interna konzistentost kognitivnih i simboličkih elemenata kulture

- Konsenzus članova organizacije oko pretpostavki, verovanja i vrednosti

- Organizaciona kultura je monolitna, homogena i interno konzistentna celina

- Nema nejasnoća i neizvesnosti u sadržaju kulture

Subkulture se mogu izdiferencirati kao:

- Horizontalno: subkulture poslovnih funkcija

- Vertikalno: subkulture menadžmenta i radnika

- Dijagonalno: subkulture po socijalnom sloju, poreklu, profesiji

Subkultura može biti u odnosu na dominantnu kulturu

- Podržavajuća

- Ortogonalna

- Kontrakultura

\subsection{Perspektiva fragmentacije}

Smatra se da nema jedinstvene organizacione kulture ali ni dominantne kulture i subkultura. Organizaciona kultura je set nekonzistentnih, labavo povezanih ili nezavisnih pretpostavki, vrednosti i normi. Neizvesnost i nejasnoće postoje na nivou pojedinih članova organizacije koji mogu držati do međusobno suprotnih verovanja i vrednosti. Članovi organizacije mogu pripadati različitim kulturnim klasterima (subkulturama) i mogu ih menjati.

\section{VEZA IZMEĐU KLIME I ZADOVOLJSTVA}

Sedamdesetih godina prošlog veka, rađena su mnoga istraživanja posvećena organizacionoj klimi, koja su pokazala njenu bliskost sa zadovoljstvom posla i performansama. Ono što je bilo jako teško odrediti jeste njihova uzročno posledična veza, odnosno da li organizaciona klima prouzrokuje zadovoljstvo poslom ili je organizaciona klima samo sinonim, kao i zadovoljstvo poslom. Litwin i Stringer su pokazali da različite organizacione klime stimulišu različite motivacije i utiču na nivo individualnih organizacionih performansi. Ivancevich i Lyon su pokazali da je smer uticaja u ovom slučaju od organizacione klime prema zadovoljstvu poslom. $\mathrm{Na}$ osnovu istraživanja se može zaključiti da je organizaciona klima povezana sa zadovoljstvom poslom, kako individualnim tako i organizacionim performansama.

\section{METODOLOGIJA ISTRAŽIVANJA}

Istaživanje je sprovedeno na teritoriji Crvenke tokom septembra 2020. godine. Ispitanici koji su učestvovali u istraživanju su zaposleni u firmi „Sigma HLOROGEN“, čije sedište se nalazi u Kuli, dok je u Crvenki odeljenje za proizvodnju. Kompanija je osnovana 1989. godine, i njena osnovna delatnost jeste proizvodnja hlorogen postrojenja i automatski doziranih sistema. Prvo Hlorogen postrojenje je proizvedeno 1996. godine. Sem navedenog, Sigma kompanija se bavi i inženjeringom i instaliranjem sistema za automatsku dezinfekciju pijaće vode.

\subsection{Hipoteze istraživanja}

U istraživanju je postavljena opšta hipoteza koja glasi:

$\mathrm{OH}$ : ,ispitanici su zadovoljni organizacionom klimom i imaju visok stepen zadovoljstva na radnom mestu“.

$\mathrm{Na}$ osnovu opšte hipoteze, formirane su tri pomoćne hipoteze:

PH1: ispitanici su pretežno zadovoljni pojedinim aspektima organizacione klime u firmi u kojoj su zaposleni.

PH2: plata i ostale novčane nagrade, kao i međuljudski odnosi su najbitniji aspekti posla, dok je nadzor od strane šefa najmanje važan aspekt posla.

PH3: zadovoljstvo poslom je značajno povezano sa pojedinim aspektima organizacione klime. 


\subsection{Diskusija hipoteza}

U istraživanju je postavljena opšta hipoteza koja glasi:

$\mathrm{OH}$ : „ispitanici su zadovoljni organizacionom klimom i imaju visok stepen zadovoljstva na radnom mestu“.

Sa ciljem da se ispita povezanost zadovoljstva poslom i pojedinih aspekata organizacione klime, primenjen je Pirsonov koeficijent korelacije r. Jedina značajna korelacija jeste između zadovoljstva poslom i mogućnosti napredovanja i usavršavanja na radnom mestu. Povezanost između ove dve varijable je umereno visoka, pozitivna i statistički značajna.

$\mathrm{Na}$ osnovu opšte hipoteze, formirane su tri pomoćne hipoteze:

PH1: ispitanici su pretežno zadovoljni pojedinim aspektima organizacione klime $\mathrm{u}$ firmi $\mathrm{u}$ kojoj su zaposleni.

Pozitivna korleacija je prisutna između zadovoljstva poslom i mogućnosti napredovanja kao i usavršavanja na radnom mestu.

PH2: plata i ostale novčane nagrade, kao i međuljudski odnosi su najbitniji aspekti posla, dok je nadzor od strane šefa najmanje važan aspekt posla.

Kao najvažnije aspekte posla ispitanici navode platu i ostale novčane nagrade, međuljudske odnose na radnom mestu, uspeh u obavljanju posla i radne uslove. Kao najmanje važni aspekti posla se izdvajaju aktivno učestvovanje u odlučivanju i nadzor na radnom mestu.

PH3: zadovoljstvo poslom je značajno povezano sa pojedinim aspektima organizacione klime.

Pozitivna korleacija je prisutna između zadovoljstva poslom i mogućnosti napredovanja kao i usavršavanja na radnom mestu. Samo tu pronalazimo pozitivnu korleaciju zadovoljstva poslom sa pojedinim aspektima organizacione klime.

\section{REZULTATI ISTRAŽIVANJA}

Najviši stepen slaganja, odnosno zadovoljstva, ispitanici navode za pitanja (koliko ste zadovoljni): Odnosima koje imate sa ostalim zaposlenim, Poslom koji obavljate, Time koliko vas vaš posao motiviše za rad, Mogućnošću napredovanja u svom poslu, Načinom primene promena i novacija, Mogućnošću usavršavanja i ličnog napredovanja u poslu i Vrstom posla ili zadacima na kojima ste angažovani. Odgovori na ovu grupu pitanja ukazuju na zaključak da su ispitanici zadovoljni, veoma zadovoljni ili u potpunosti zadovoljni ovim aspektima posla.

Naredna grupa pitanja, u kojoj je stepen zadovoljstva ispitanika pretežno u rasponu od ,zadovoljan“ do ,veoma sam zadovoljan“ obuhvata pitanja (koliko ste zadovoljni):

- Komunikacijom i načinom prenošenja informacija $u$ vašoj organizaciji,

- Sigurnošću posla koji sada obavljate,

- Stepenom u kome možete da se poistovetite s reputacijom i ciljevima svoje organizacije,

- Načinom kontrole koju sprovode vaši pretpostavljeni,
- Mogućnostima za učestvovanje u donošenju važnih odluka,

- Stepenom u kome posao koji obavljate zahteva.

Poslednja grupa pitanja obuhvata pitanja na koja ispitanici odgovaraju sa različitim tvrdnjama, koje variraju od nezadovoljstva do zadovoljstva. Ova grupa obuhvata pitanja (koliko ste zadovoljni):

- Mogućnostima koje vam posao pruža za ostvarenje ličnih težnji i ambicija,

- Stepenom slobode i fleksibilnosti koji imate u obavljanju svog posla,

- Psihološkom klimom i atmosferom u svojoj organizaciji,

- Visinom plate u odnosu na vaše radno iskustvo,

- Načinom organizacije vašeg preduzeća,

- Količinom posla koji obavljate i

- Merom u kojoj vas vaš posao obogaćuje.

\section{ZAKLJUČAK}

Kada biste se kod ljudi raspitivali o njihovom poslu , verovatno biste saznali da imaju čvrste stavove o tome šta osecaju (na primer: .,Zaista mi se ne dopada ovo što radim."), Sta veruju (na primer: ,.Mi društvenoj zajednici pružamo važne usluge."), i Sta nameravaju da urade (na primer: „Potražiću novo radno mesto.").

Različiti stavovi (pozitivni i negativni) koje ljudi imaju prema svom poslu nazivaju se zadovoljstvo poslom. Zadovoljstvo poslom je prijatno osećanje koje je rezultat percepcije da posao ispunjava ili dozvoljava ispunjenje važnih poslovnih vrednosti.

\section{LITERATURA}

[1] Bahtijarević-Šiber, F. (1999). Menadžment ljudskih potencijala, Golden marketing, Zagreb

[2] Grubić-Nešić L. (2005). Razvoj ljudskih resursa, AB Print, Novi Sad

[3] Ratković-Njegovan, B. (2012). Organizaciona socijalizacija- Skripta, Fakultet tehničkih nauka, Novi Sad

[4] Grubić-Nesić L. (2015). Motivacija za rad, skripta, Fakultet tehničkih nauka, Novi Sad

\section{Kratka biografija:}

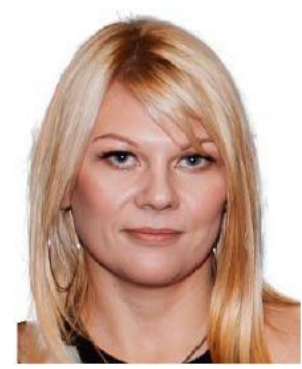

Jasmina Sudar rođena je u Somboru 1985. godine. Master rad na Fakultetu tehničkih nauka iz oblasti Inženjerski menadžment-Ljudski resursi odbranila je 2020. godine. 